\title{
Simultaneous Distillation Extraction of Some Volatile Flavor Components from Pu-erh Tea Samples-Comparison with Steam Distillation-Liquid/Liquid Extraction and Soxhlet Extraction
}

\author{
Xungang Gu, ${ }^{1}$ Zhengzhu Zhang, ${ }^{1}$ Xiaochun Wan, ${ }^{1}$ Jingming Ning, \\ Chengcheng Yao, ${ }^{1}$ and Wanfang Shao ${ }^{2}$ \\ ${ }^{1}$ Key Lab of Tea Biochemistry \& Biotechnology, Ministry of Agriculture, Anhui Agricultural University, Hefei 230036, China \\ ${ }^{2}$ Institute of Pu-erh Tea, Yunnan Agricultural University, Kunming 650201, China \\ Correspondence should be addressed to Xiaochun Wan, xcwan@ahau.edu.cn
}

Received 16 August 2009; Revised 25 November 2009; Accepted 3 December 2009

Recommended by Shaoping Li

\begin{abstract}
A simutaneous distillation extraction (SDE) combined GC method was constructed for determination of volatile flavor components in Pu-erh tea samples. Dichloromethane and ethyl decylate was employed as organic phase in SDE and internal standard in determination, respectively. Weakly polar DB-5 column was used to separate the volatile flavor components in GC, 10 of the components were quantitatively analyzed, and further confirmed by GC-MS. The recovery covered from $66.4 \%-109 \%$, and repeatability expressed as RSD was in range of $1.44 \%-12.6 \%$. SDE was most suitable for the extraction of the anlytes by comparing with steam distillation-liquid/liquid extraction and Soxhlet extraction. Commercially available Pu-erh tea samples, including Pu-erh raw tea and ripe tea, were analyzed by the constructed method. the high-volatile components, such as benzyl alcohol, linalool oxide, and linalool, were greatly rich in Pu-erh raw teas, while the contents of 1,2,3-Trimethoxylbenzene and 1,2,4-Trimethoxylbenzene were much high in $\mathrm{Pu}$-erh ripe teas.
\end{abstract}

Copyright ( $) 2009$ Xungang Gu et al. This is an open access article distributed under the Creative Commons Attribution License, which permits unrestricted use, distribution, and reproduction in any medium, provided the original work is properly cited.

\section{Introduction}

$\mathrm{Pu}$-erh tea is a special tea species in China and has become one of the most popular beverages in southwestern China and Southeast Asian, owing to its special flavour properties and potential healthy benefits [1]. It is originated from Yunnan province (China) through a special post-fermentative process, using crude green tea prepared from the leaves of C. sinensis var. assamica as original materials [2]. Because $\mathrm{Pu}$-erh tea has a malty flavour and low-stimulation taste in tea infusions [1] which may fit female appetite, recent years, interest in the flavor and the healthy properties and the related scientific investigations were increasing $[3,4]$. Up to now, a little information on the relationship of the chemical composition to the flavor is available.

Volatile flavor component is one of the most important factors to influence the flavor, taste, and quality of $\mathrm{Pu}-$ erh tea [1], in which the contents are different from the green and black tea because of different processing procedure and variety of species and cultivar [5]. Investigation on the components in green and black tea are reported elsewhere [6], yet few on those in Pu-erh teas. In order to explore the influence of those components to flavor, taste, and quality, quantitative analysis of main volatile flavor components in $\mathrm{Pu}$-erh tea is one of the key procedures.

Sample preparation is a critical step in analytical procedure for $\mathrm{Pu}$-erh tea. Compatible extraction technique can provide a convincing result for determination of target components. For analysis of volatile components or essential oils, several extraction techniques, including Soxhlet extraction [7], liquid-liquid extraction (LLE) [8], simutaneous distillation-solvent extraction (SDE) [9], solid phase microextraction (SPME) [10], and headspace microextraction (HSME) [11] and so forth, had been used to diferent matices.

Soxhlet extraction is a classical method for decades in extraction of organic compounds from solid sample, and this apparatus has been developed to several types for special 
use [12]. It is considered to be a "thorough" extraction method because the organic phase cooled from condensation tube continuously passes through the target solid sample for hours. However, poor recovery commonly occurred for extraction of high-volatile or heat-labile compounds.

LLE is a conventional method for isolation of all boiling range volatile compounds, based on the compatibility of compounds with organic phase selected. The main disadvantage is solvent-consuming, tedious and, low-recovery for some target compounds [13].

SDE, proposed by Godefroot and so forth [14], has been widely applied to analysis of volatile components in tea samples [15]. Although low recovery has been found for extracting the most volatile or heat-labile components, this technique has achieved higher recoveries and greater repeatability of volatile or semi-volatile and heat-stable components than other isolation technique such as SPME [10] or HSME when low water temperature in the circulating system was used.

SPME and HSME are relatively new techniques that are able to address the need for concentrating the components in the headspace $[10,11]$. Both of them use a small piece of fused silica, on which a liquid or solid phase, similar to a GC stationary phase, has been coated to absorb the desired components and concentrate them on the fibre. Thus the two techniques are more sensitive for the isolation of high volatile components than SDE, while less sensitive and lower repeatability for the low volatiles than SDE.

Conventionally, $\mathrm{Pu}$-erh tea is condensed to a pie-like tea-biscuit in the final processing procedure. Extraction of the volatile flavor components will be different from the green and black tea. In order to select the best extraction technique for studying the volatile flavor components of $\mathrm{Pu}$-erh tea, a modified SDE was evaluated for quantitative determination of the analytes using ethyl decylate as internal standard, and the two classical techniques, steam distillation-liquid/liquid extraction and Soxhlet extraction, were compared.

\section{Experimental}

2.1. Specimens. $\mathrm{Pu}$-erh tea samples were obtained from Dayi Limited Incorporation (Menghai, Yunnan, China). The sample was dried at $40^{\circ} \mathrm{C}$ in electric oven for $6 \mathrm{~h}$, ground to 30-60 mesh, and sealed for use.

2.2. Chemicals and Reagents. The reference volatile chemicals were purchased from Sigma (St. Louis, MO, USA). The stock solution was prepared by dissolving single solid/liquid standard in dichloromethane to an appropriate concentration depending on the content in Pu-erh tea. Ultra-pure water was obtained from a Milli-Q water purification system (Pall Co, IL, USA). Chromatography-grade dichloromethane was purchased from Tedia (OH, USA). The other solvents used in the test were all of analytical-grade and disdillated before use.

\subsection{Sample Preparation}

2.3.1. Simultaneous Distillation-Solvent Extraction (SDE). SDE was carried out in a microversion apparatus, as described elsewhere. Dichloromethane and ethyl decylate were employed as solvent and internal standards, respectively. For each extraction, $15 \mathrm{~g}$ of tea sample, $10 \mathrm{~g}$ sodium sulphate, $100 \mu \mathrm{L}$ internal standard solution and $300 \mathrm{~mL}$ ultra-pure water were placed in a $1 \mathrm{~L}$ flask, $50 \mathrm{~mL}$ dichloromethane was in a $100 \mathrm{~mL}$ flask, and temperature of the circulating water system was operated at $8^{\circ} \mathrm{C}$. Stream distillation was stopped after $2 \mathrm{~h}$, while the solvent extraction was continued for a further $15 \mathrm{~min}$. The extract was concentrated to $1 \mathrm{~mL}$ at $10^{\circ} \mathrm{C}$ by a nitrogen-purge apparatus (Shanghai ANPEL Scientific Instrument Co. LTD). The concentated solution was dehydrated with anhydrous sodium sulphate for at least $12 \mathrm{~h}$, of which $2 \mu \mathrm{L}$ was injected to GC or GC-MS system for analysis.

\subsubsection{Steam Distillation-Liquid/Liquid Extraction (SD-LLE).} For SD-LLE, $15 \mathrm{~g}$ of tea sample, $10 \mathrm{~g}$ sodium sulphate, $100 \mu \mathrm{L}$ internal standard solution and $500 \mathrm{~mL}$ ultra-pure water were placed in a $1 \mathrm{~L}$ distillation flask, respectively. The flask was connected to a condensation tube. Stream distillation was not stopped until $200 \mathrm{~mL}$ effluent liquid was collected. The liquid was transferred to a $500 \mathrm{~mL}$ of separation funnel and then extracted three times $(30 \mathrm{~mL}$ $\times 3$ ) using dichloromethane. The extracted organic phase was combined and concentrated to $1 \mathrm{~mL}$ at $30^{\circ} \mathrm{C}$ by a nitrogen-purge apparatus after internal standard was added.

2.3.3. Soxhlet Extraction. $15 \mathrm{~g}$ of tea sample containing $100 \mu \mathrm{L}$ internal standard solution were placed in Soxhlet's apparatus and $50 \mathrm{~mL}$ of dichloromethane in an $150 \mathrm{~mL}$ distillation flask. At both ends of the sample in Soxhlet's apparatus, there are $2 \mathrm{~cm}$-height of Celite to help fix the sample. Extraction was carried out at $50^{\circ} \mathrm{C}$ for 2 hours, and extraction was concentrated to $1 \mathrm{~mL}$ at $30^{\circ} \mathrm{C}$ by a nitrogen-purge apparatus after internal standard was added.

\subsection{Apparatus}

2.4.1. GC Conditions. The concentrated extracts were chromtographed by an HP 6890 series GC system (Agilent, USA). A $30 \mathrm{~m} \times 0.25 \mathrm{~mm}$ DB-5 quartz capillary column (Supelco, Bellefonte, PA, USA) with $0.25 \mu \mathrm{m}$ film thickness was used to resolve the volatiles. Temperature programming was as follows: initial oven temperature was set at $60^{\circ} \mathrm{C}$ and kept for $3 \mathrm{~min}$, then raised to $200^{\circ} \mathrm{C}$ at a ramp of $4^{\circ} \mathrm{C} / \mathrm{min}$ and kept for $2 \mathrm{~min}$; to $210^{\circ} \mathrm{C}$ at of $1^{\circ} \mathrm{C} / \mathrm{min}$ and kept for $2 \mathrm{~min}$; and finally, it was raised to $270^{\circ} \mathrm{C}$ and kept for $7 \mathrm{~min}$. Nitrogen was used as carrier gas with column head pressure at $12.26 \mathrm{kPa}$ in constant pressure mode. Injection volume was $2 \mu \mathrm{L}$. Programming split/splitless injection temperature was set at $260^{\circ} \mathrm{C}$ with split ratio of $10: 1$ and FID detector at $280^{\circ} \mathrm{C}$. 


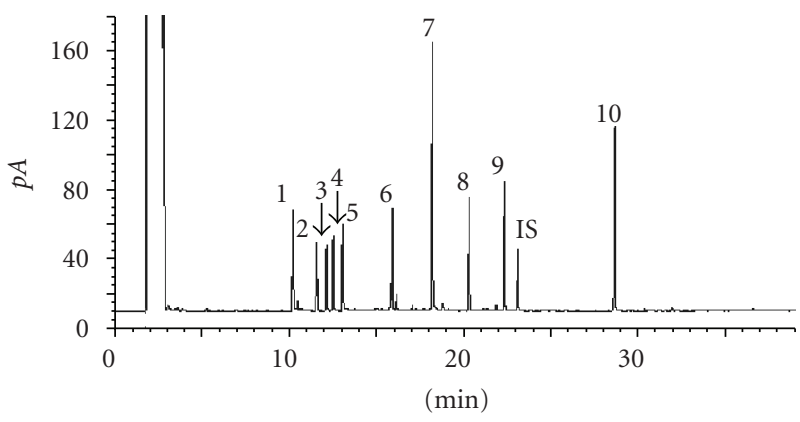

(a)

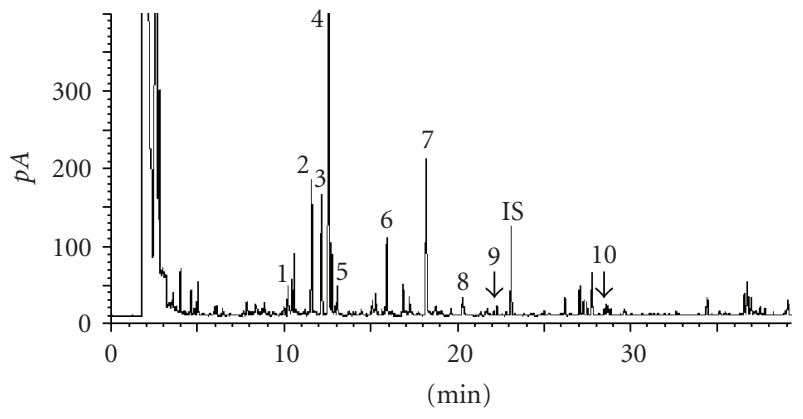

(b)

Figure 1: (a) Chromatogram of standard compounds, and (b) Pu-erh raw tea analyzed by GC-FID. 1 = Benzyl alcohol; 2,3 = Linalool oxide; $4=$ Linalool; $5=$ Phenethyl alcohol; $6=\alpha$ Terpineol; 7 = Geraniol; $8=1,2,3$-Trimethoxylbenzene; $9=1,2,4$ Trimethoxylbenzene; IS = internal standard; $10=$ Nerolidol.

2.4.2. GC-MS Conditions. Auto system Shimaszu QP 2010 GC-MS was employed for qualitative analysis to confirm the target components. GC temperature programming. The oven temperature was set at $50^{\circ} \mathrm{C}$ and kept for 2 min, then raised to $60^{\circ} \mathrm{C}$ at a ramp of $1^{\circ} \mathrm{C} / \mathrm{min}$ and kept for $2 \mathrm{~min}$, to $200^{\circ} \mathrm{C}$ at of $4^{\circ} \mathrm{C} / \mathrm{min}$ and kept for $2 \mathrm{~min}$, and finally, to $270^{\circ} \mathrm{C}$ at $10^{\circ} \mathrm{C} / \mathrm{min}$ and kept for $5 \mathrm{~min}$. Carrier gas: helium. The mass spectrometry was operated at $200^{\circ} \mathrm{C}$ in the electron impact mode $(70 \mathrm{eV})$, Scanning from $\mathrm{m} / \mathrm{z} 40$ to 600 in $0.3 \mathrm{~s}$ with an $0.2 \mathrm{~s}$ interval time of the scan; the temperature of the GC-MS interface was $280^{\circ} \mathrm{C}$; the voltage of the photoelectric multiplier tube (PMT) was $200 \mathrm{~V}$. The mass spectral identifications of the target components were carried out by comparing to the NIST 107 (National Institute of Standards and Technology, Gaithersburg, USA) mass spectral library as well as to Wiley 6.0 (Wiley, New York, NY, USA) mass spectral library.

\section{Results and Discussion}

3.1. Chromatographic Performance. For GC separation of volatile components in tea samples, BP-20 SGE column (polar column, $30 \mathrm{~m} \times 0.25 \mathrm{~mm}$ i.d. film thickness $0.25 \mu \mathrm{m}$ ) was commonly used for quantitative analysis [16]. In this work, DB-5 column $(30 \mathrm{~m} \times 0.25 \mathrm{~mm}$ i.d. film thickness $0.25 \mu \mathrm{m})$ was employed to separate the target components with temperature programming described above, and

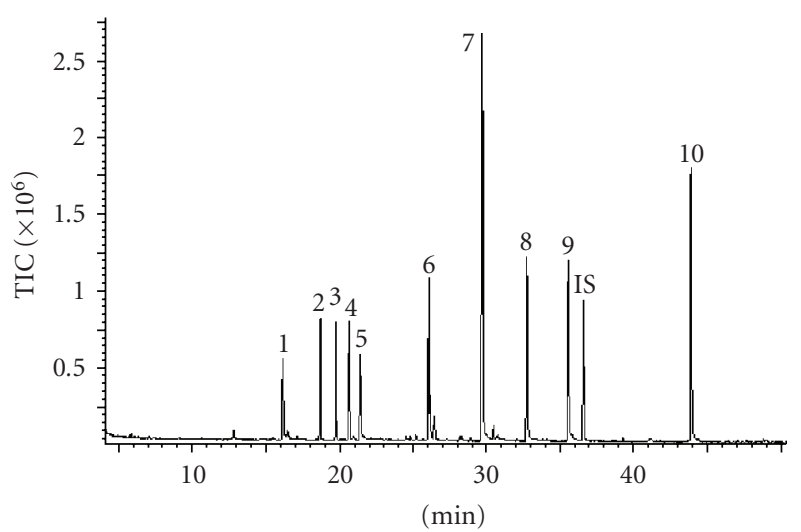

(a)

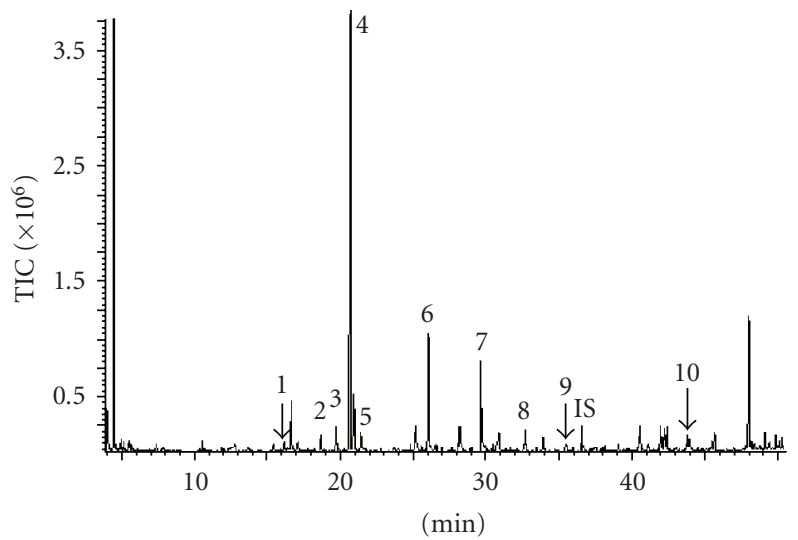

(b)

Figure 2: (a) TIC chromatogram of standard compounds, and (b) Pu-erh raw tea analyzed by GC-MS. 1 = Benzyl alcohol; 2,3 = Linalool oxide; $4=$ Linalool; $5=$ Phenethyl alcohol; $6=\alpha$ Terpineol; 7 = Geraniol; $8=$ 1,2,3-Trimethoxylbenzene; $9=1,2,4$ Trimethoxylbenzene; IS = internal standard; $10=$ Nerolidol.

the chromatograms of standard compounds by GC-FID and GC-MS was shown in Figures 1(a) and 2(a). From the chromatograms, it can be seen each peak of the target compounds was baseline separated, and separating degree between two vicinity peaks was beyond 2 , confirming weakpolar capillary column can be used to separate the target components if GC separation condition was well optimized. According to GC-FID chromatogram, we calculated the relative factor of each of the standard compounds, it was shown in Table 1, and the relative factor was used to determination of the corresponding components in real $\mathrm{Pu}$ erh teas.

Figures 1(b) and 2(b) show the chromatograms of Puerh raw tea that was obtained from GC-FID and GC-MS determination, in which the target peaks of real sample could be easily discerned and accurately quantified. The mass spectra of each target peaks in Figure 2(b) was checked by NIST or Wiley mass spectral library respectively, and campared with those in Figure 2(a), confirming that each mass spectra of the components was the same as those of the corresponding standard compound, and no interference was appeared in the target peaks. 
TABLE 1: Parameters of standard compounds in chromatography.

\begin{tabular}{|c|c|c|c|c|}
\hline Compound & $\begin{array}{l}\text { Retention time } \\
(\min )\end{array}$ & $\begin{array}{c}\text { Concentration } \\
\left(\mu \mathrm{g} \cdot \mathrm{mL}^{-1}\right)\end{array}$ & Peak area & Relative factor* \\
\hline Benzyl alcohol & 10.23 & 26.88 & 194.1 & 1.0951 \\
\hline Linalool oxide & $11.59+12.15$ & 70.61 & 275.1 & 2.0296 \\
\hline Linalool & 12.53 & 55.18 & 153.1 & 2.8500 \\
\hline Phenethy alcohol & 13.07 & 28.24 & 173.1 & 1.2901 \\
\hline$\alpha$-Terpineol & 15.92 & 27.02 & 217.6 & 0.9884 \\
\hline Geraniol & 18.21 & 99.00 & 626.5 & 1.2496 \\
\hline 1,2,3-Trimethoxylbenzene & 20.32 & 46.57 & 233.8 & 1.5751 \\
\hline 1,2,4-Trimethoxylbenzene & 22.35 & 48.22 & 271.8 & 1.4029 \\
\hline IS & 23.10 & 17.30 & 136.8 & 1.0000 \\
\hline Nerolidol & 28.65 & 52.56 & 439.7 & 0.9452 \\
\hline
\end{tabular}

* Relative factor: $f=\left(\mathrm{C}_{i} \times \mathrm{A}_{i s}\right) /\left(\mathrm{A}_{i} \times \mathrm{C}_{i s}\right)$

TABLE 2: Comparison of SDE, SD-LLE and Soxhlet extraction for volatile flavor components from Pu-erh tea $\left(\mu \mathrm{g} \cdot \mathrm{mL}^{-1}\right)$.

\begin{tabular}{|c|c|c|c|c|}
\hline \multirow{2}{*}{ Peak no. } & \multirow{2}{*}{ Compound name } & \multicolumn{3}{|c|}{ Extraction technique } \\
\hline & & $\mathrm{SDE}^{1}$ & SD-LLE ${ }^{2}$ & Soxhlet $^{2}$ \\
\hline 1 & Benzyl alcohol & 20.13 & 16.06 & 15.10 \\
\hline 2 and 3 & Linalool oxide* & 61.05 & 33.69 & 23.96 \\
\hline 4 & Linalool & 658.1 & 280.5 & 36.62 \\
\hline 5 & Phenethyl alcohol & 18.83 & 17.19 & 10.54 \\
\hline 6 & $\alpha$-Terpineol & 59.04 & 25.63 & 51.62 \\
\hline 7 & Geraniol & 70.35 & 30.72 & 4.061 \\
\hline 8 & 1,2,3-Trimethoxylbenzene & 13.26 & 4.305 & 11.84 \\
\hline 9 & 1,2,4-Trimethoxylbenzene & 3.174 & 4.294 & 5.746 \\
\hline 10 & Nerolidol & 4.676 & 4.421 & 3.955 \\
\hline
\end{tabular}

* Relative factor: $f=\left(\mathrm{C}_{i} \times \mathrm{A}_{i s}\right) /\left(\mathrm{A}_{i} \times \mathrm{C}_{i s}\right)$

Comparing Figures 1(b) and 2(b), we found that both GC-FID and GC-MS separation methods can be applied to quantitative analysis of volatile flavor components in $\mathrm{Pu}$-erh teas. Nevertheless, quantitative determination of the target components using GC-FID was more cost-saving than doing GC-MS, so the rest determinations for all of the samples were carried out in GC-FID.

3.2. Extraction Solvent and Time of SDE. During SDE operation, dichloromethane and diethylether are the most suitable extraction solvents for extraction of volatile components because of their weakly polar characteristics $[15,17]$. In this experimental, we select dichloromethane as extraction solvent for SDE, due to its property of low combustion, and higher boiling point $\left(40^{\circ} \mathrm{C}\right)$ than diethylether $\left(35^{\circ} \mathrm{C}\right)$ thus liable to storage.

Zhu et al. had applied SDE to extract volatile constitutes in green tea, confirming of $2 \mathrm{~h}$ was adequate to extract all the target compounds [15]. Initially, we operated SDE apparatus as $\mathrm{Zhu}$ et al. done, and found that there are about $6 \%$ of target components dwelling on the tea residue. This is because $\mathrm{Pu}$-erh tea was condensed to a pie-like shape, and the components were more difficult to release from tea matrix although the teas had been ground to 30-60 mesh. Then we modified this method by adding $10 \mathrm{~g}$ of sodium sulphate to the $1 \mathrm{~L}$ of steam flask containing $300 \mathrm{~mL}$ of water, and then operating SDE device. After $2 \mathrm{~h}$ of SDE and a further $15 \mathrm{~min}$ of the solvent extraction, the tea residue was re-extracted by SDE, we found the area of the target peaks were less than $2 \%$ of the total. Obviously, boiling point of water in steam flask was enhanced by adding sodium sulphate, accelerating the releasing velocity of target compounds.

3.3. Recovery and Repeatability. To confirm the repeatability, parallel experimental was carried out. Five Pu-erh tea samples were extracted by SDE described above, respectively. The relative standard deviations (RSD) were in range of $1.44 \%-$ $12.6 \%$, which were shown in Table 3 . To check accuracy of SDE for volatile flavor components, a known amount of standard solutions were added to aliquot of Pu-erh tea. The adding level and corresponding recoveries were listed in Table 3. The recoveries of 10 target compounds were in the range of $66.4 \%-109 \%$.

3.4. Comparison of SDE, SD-LLE and Soxhlet Extraction. For quantitative extraction of volatile flavor components from complex matrices, common technique used is SDE. Because both liquid/liquid extraction and Soxhlet extraction are classical techniques $[8,10]$, in this test, the modified classical techniques were compared with SDE in extraction 
TABLE 3: Recovery and repeatability.

\begin{tabular}{lccccc}
\hline Compound name & $\begin{array}{c}\text { SDE } \\
\left(\mu \mathrm{g} \cdot \mathrm{mL}^{-1}\right)\end{array}$ & $\begin{array}{c}\text { Spiked level } \\
\left(\mu \mathrm{g} \cdot \mathrm{mL}^{-1}\right)\end{array}$ & $\begin{array}{c}\text { Mean } \\
\left(\mu \mathrm{g} \cdot \mathrm{mL}^{-1}\right)\end{array}$ & $\begin{array}{c}\text { Recovery } \\
(\%, n=3)\end{array}$ & $\begin{array}{c}\text { RSD } \\
(\%, n=5)\end{array}$ \\
\hline Benzyl alcohol & 20.13 & 13.44 & 33.96 & 103 & 10.3 \\
Linalool oxide & 61.05 & 543.3 & 488.1 & 78.6 & 10.7 \\
Linalool & 658.1 & 689.8 & 1321 & 96.1 & 5.73 \\
Phenethyl alcohol & 18.83 & 14.12 & 33.72 & 105 & 1.44 \\
$\alpha$-Terpineol & 59.04 & 13.51 & 73.29 & 105 & 12.6 \\
Geraniol & 70.35 & 99.00 & 178.3 & 109 & 7.49 \\
1,2,3-Trimethoxylbenzene & 13.26 & 23.28 & 37.22 & 103 & 10.3 \\
1,2,4-Trimethoxylbenzene & 3.174 & 12.05 & 11.18 & 66.4 & 12.3 \\
Nerolidol & 4.676 & 5.256 & 8.772 & 77.9 & 8.54 \\
\hline
\end{tabular}

TABLE 4: Contents of volatile components in tea samples $\left(\mu \mathrm{g} \cdot \mathrm{g}^{-1}\right)$.

\begin{tabular}{|c|c|c|c|c|c|c|c|c|c|c|}
\hline \multirow{3}{*}{ Compound } & \multirow{3}{*}{ Green tea } & \multirow{3}{*}{ Black tea } & \multicolumn{8}{|c|}{ Production date of Pu-erh tea } \\
\hline & & & \multicolumn{4}{|c|}{$\mathrm{Pu}$-erh ripe tea } & \multicolumn{4}{|c|}{ Pu-erh raw tea } \\
\hline & & & 2005 & 2006 & 2007 & 2008 & 2005 & 2006 & 2007 & 2008 \\
\hline Benzyl alcohol & 80.7 & 16.8 & 0.132 & 0.229 & 0.329 & 0.263 & 1.15 & 0.634 & 0.587 & 1.34 \\
\hline Linalool oxide & 488 & 13.9 & 3.25 & 4.47 & 5.70 & 3.75 & 4.02 & 4.33 & 5.10 & 4.07 \\
\hline Linalool & 22.3 & 15.8 & 4.72 & 3.61 & 5.26 & 2.84 & 51.4 & 40.3 & 53.7 & 43.9 \\
\hline Phenethyl alcohol & 54.6 & 14.9 & 0.377 & 0.819 & 0.829 & 0.832 & 1.34 & 0.811 & 0.975 & 1.26 \\
\hline$\alpha$-Terpineol & 138 & 2.14 & 1.87 & 1.86 & 2.24 & 1.45 & 0.554 & 1.77 & 0.447 & 3.94 \\
\hline Geraniol & 5.28 & 26.3 & 0.412 & 0.300 & 0.597 & 0.442 & 5.26 & 5.10 & 4.72 & 4.69 \\
\hline 1,2,3-Trimethoxylbenzene & $\mathrm{ND}$ & $\mathrm{ND}$ & 6.35 & 16.4 & 11.3 & 14.1 & 0.707 & 0.645 & 0.815 & 0.884 \\
\hline 1,2,4-Trimethoxylbenzene & ND & ND & 4.15 & 5.62 & 4.08 & 9.91 & 0.211 & 1.34 & 0.099 & 0.212 \\
\hline Nerolidol & 4.62 & 2.18 & 0.223 & 0.193 & 0.071 & 0.043 & 0.385 & 0.512 & 0.175 & 0.312 \\
\hline
\end{tabular}

of the volatile flavor components from $\mathrm{Pu}$-erh tea in order to select the best one for sample preparation. the results were shown in Table 2. Generally, SDE was the best one among them, because the amounts of the components extracted were greater than those by employing SD-LLC or Soxhlet for the high-volatile components such as benzyl alcohol, linalool oxide, and linalool. This may attributes to the fact that SDE was a closed and continuous extraction system, in which the target components can be "thoroughly" transferred to organic phase. Furthermore, the temperature of the circulating water in SDE was set at $8^{\circ} \mathrm{C}$, reducing the lose of the high-volatile components. As for extraction of the low-volatile components in pu-erh tea, such as 1,2,4Trimethoxylbenzene, SDE is less poor compared with Soxhlet extraction, probably due to the characteristics of highboiling point and incompatibility with water steam.

Although SD-LLE shares a same extraction principle with SDE, the limitation of the technique is clear in Table 2. This is due to its open steam distillation system and following step-liquid-liquid extraction. During this procedure, not only high-volatile components such as benzyl alcohol, linalool oxide, and linalool and so forth had a chance to escape from the distillation system, but the analytes hardly transferred to organic phase. However, for 1,2,3- and 1,2,4-trimethoxylbenzene, contradictory results appeared as Table 2 showed. We could not confirm whether isomerization reaction was happened between the two compounds during extraction, and further investigation was beyond the work.

Soxhlet extraction was a classical technique to extract essential oil from natural product [7]. Table 2 shows that it can almost "exhaustively" extract all the 1,2,3- and 1,2,4trimethoxylbenzene from $\mathrm{Pu}$-erh tea compared with SDE, nevertheless it is very poor for benzyl alcohol, linalool oxide, linalool, phenethyl alcohol, and geraniol. These findings indicate Soxhlet was suitable for high-boiling point (lowvolatile) compounds such as essential oil [18]. As for the trace high-volatile component, SDE was appreciated.

3.5. Determination of Tea Samples. Using the present SDE technique following GC determination, we analyzed several tea samples, including four $\mathrm{Pu}$-erh ripe tea, four $\mathrm{Pu}$-erh raw tea, one green tea (Huangshan, Anhui) and one black tea (Qimen, Anhui), and the contents of the target volatile components were shown in Table 4. It can be seen that the content of high volatile components, such as benzyl alcohol, linalool oxide, linalool in raw teas are higher than those in ripe teas, these findings are mainly due to the high temperature $\left(45-55^{\circ} \mathrm{C}\right)$ during the pile-fermentation process of ripe $\mathrm{Pu}$-erh teas, leading to the lose of these components [19]. However, in raw teas, the content of 1,2,3and 1,2,4-Trimethoxylbenzene are much lower than those in ripe teas, this is because microbes play an important role 
in the synthesis of the two compounds during the pilefermentation process of ripe $\mathrm{Pu}$-erh teas [20], which promote reaction procedure of methylation.

Generally, the contents of the volatile components in the green and the black teas are higher than those in $\mathrm{Pu}$-erh teas, except for 1,2,3- and 1,2,4-Trimethoxylbenzene, which are not found in both of teas, probably due to lack of post-pilefermentation process in manufacture, and linalool, lower than those in $\mathrm{Pu}$-erh raw teas due to different cultivar, variety of species and processing procedure [5].

\section{Conclusion}

SDE combined GC method was constructed for determination of volatile flavor components in $\mathrm{Pu}$-erh tea samples. 10 of volatile flavor components were quantitatively determined, and the recoveries and RSDs were in the range of $66.4 \%-109 \%$ and $1.44 \%-12.6 \%$, respectively. The method was compared with SD-LLE and Soxhlet extraction, comfirming SDE was suitable for Pu-erh teas among them. $\mathrm{Pu}$-erh raw tea and ripe tea samples were analyzed by the method, indicating the high-volatile components, such as benzyl alcohol, linalool oxide, and linalool, were rich in $\mathrm{Pu}$-erh raw teas, while the contents of 1,2,3- and 1,2,4Trimethoxylbenzene were much high in $\mathrm{Pu}$-erh ripe teas.

\section{Acknowledgments}

The authors thank national post-doctorial science and technology fund committee (No. 20080430757), national support plan program of science and technology (No. 2007BAD58B04), and the fund of technical system of modern agricultural industry for financial support.

\section{References}

[1] Y. Liang, L. Zhang, and J. Lu, "A study on chemical estimation of Pu-erh tea quality," Journal of the Science of Food and Agriculture, vol. 85, no. 3, pp. 381-390, 2005.

[2] Z.-H. Zhou, Y.-J. Zhang, M. Xu, and C.-R. Yang, "Puerins A and B, two new 8-C substituted flavan-3-ols from Pu-er tea," Journal of Agricultural and Food Chemistry, vol. 53, no. 22, pp. 8614-8617, 2005.

[3] S.-C. Wu, G.-C. Yen, B.-S. Wang, et al., "Antimutagenic and antimicrobial activities of Pu-erh tea," LWT-Food Science and Technology, vol. 40, no. 3, pp. 506-512, 2007.

[4] D.-J. Yang and L. S. Hwang, "Study on the conversion of three natural statins from lactone forms to their corresponding hydroxy acid forms and their determination in Pu-erh tea," Journal of Chromatography A, vol. 1119, no. 1-2, pp. 277-284, 2006.

[5] K.-C. Jeng, C.-S. Chen, Y.-P. Fang, R. C.-W. Hou, and Y.-S. Chen, "Effect of microbial fermentation on content of statin, GABA, and polyphenols in Pu-erh tea," Journal of Agricultural and Food Chemistry, vol. 55, no. 21, pp. 8787-8792, 2007.

[6] D. Wang, T. Yoshimura, K. Kubota, and A. Kobayashi, "Analysis of glycosidically bound aroma precursors in tea leaves. 1. Qualitative and quantitative analyses of glycosides with aglycons as aroma compounds," Journal of Agricultural and Food Chemistry, vol. 48, no. 11, pp. 5411-5418, 2000.
[7] M. Z. Ozel and H. Kaymaz, "Superheated water extraction, steam distillation and Soxhlet extraction of essential oils of Origanum onites," Analytical and Bioanalytical Chemistry, vol. 379, no. 7-8, pp. 1127-1133, 2004.

[8] E. F. López and E. F. Gómez, "Comparison of solvents for determination of monoterpenes in wine using liquid-liquid extraction," Chromatographia, vol. 52, no. 11-12, pp. 798-802, 2000.

[9] S. Selli and G. G. Cayhan, "Analysis of volatile compounds of wild gilthead sea bream (Sparus aurata) by simultaneous distillation-extraction (SDE) and GC-MS," Microchemical Journal, vol. 93, no. 2, pp. 232-235, 2009.

[10] J. Cai, B. Liu, and Q. Su, "Comparison of simultaneous distillation extraction and solid-phase microextraction for the determination of volatile flavor components," Journal of Chromatography A, vol. 930, no. 1-2, pp. 1-7, 2001.

[11] M. J. Heravi and H. Sereshti, "Determination of essential oil components of Artemisia haussknechtii Boiss. using simultaneous hydrodistillation-static headspace liquid phase microextraction-gas chromatography mass spectrometry," Journal of Chromatography A, vol. 1160, no. 1-2, pp. 81-89, 2007.

[12] J. Ruiz-Jiménez, F. Priego-Capote, and M. D. Luque de Castro, "FT-midIR determination of fatty acid profiles, including trans fatty acids, in bakery products after focused microwaveassisted Soxhlet extraction," Analytical \& Bioanalytical Chemistry, vol. 385, no. 8, pp. 1532-1537, 2006.

[13] E. Sánchez-Palomo, M. E. Alañón, M. C. Díaz-Maroto, M. A. González-Viñas, and M. S. Pérez-Coello, "Comparison of extraction methods for volatile compounds of Muscat grape juice," Talanta, vol. 79, no. 3, pp. 871-876, 2009.

[14] M. Godefroot, P. Sandra, and M. Verzele, "New method for quantitative essential oil analysis," Journal of Chromatography A, vol. 203, pp. 325-335, 1981.

[15] M. Zhu, E. Li, and H. He, "Determination of volatile chemical constitutes in tea by simultaneous distillation extraction, vacuum hydrodistillation and thermal desorption," Chromatographia, vol. 68, no. 7-8, pp. 603-610, 2008.

[16] R. Rawat and A. Gulati, "Seasonal and clonal variations in some major glycosidic bound volatiles in Kangra tea (Camellia sinensis (L.) O. Kuntze)," European Food Research \& Technology, vol. 226, no. 6, pp. 1241-1249, 2008.

[17] R. Gyawali, H.-Y. Seo, S.-L. Shim, et al., "Effect of $\gamma$-irradiaton on the volatile compounds of licorice (Glycyrrhiza uralensis Fischer)," European Food Research \& Technology, vol. 226, no. 3, pp. 577-582, 2008.

[18] M. M. Schantz, B. A. Benner Jr., S. N. Chesler, et al., "Preparation and analysis of a marine sediment reference material for the determination of trace organic constituents," Fresenius' Journal of Analytical Chemistry, vol. 338, no. 4, pp. 501-514, 1990.

[19] M. Z. Liang, L. F. Xia, L. B. Chen, et al., "Study on variation fo physics and chemisty index during pile-fermentation of $\mathrm{Pu}-$ erh-tea," Chinese Agricultural Science Bulletin, vol. 22, no. 10, pp. 321-325, 2006.

[20] L. F. Zhao, Y. J. Xu, and H. J. Zhou, "Research on microbes improve quality and flavor of Pu'er tea in solid fermentation," Food Research and Development, vol. 27, no. 4, pp. 155-156, 2006. 


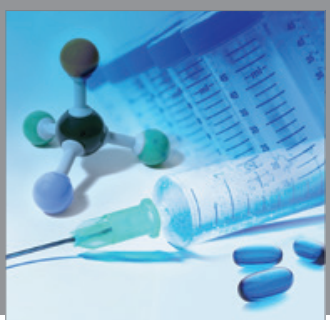

International Journal of

Medicinal Chemistry

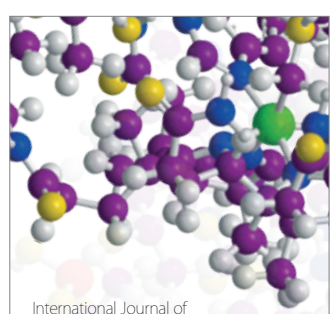

Carbohydrate Chemistry

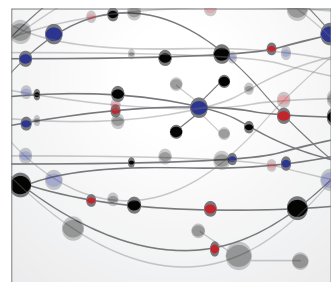

The Scientific World Journal
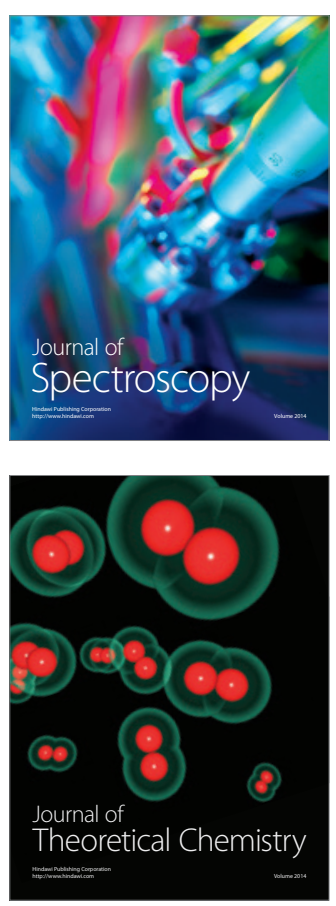
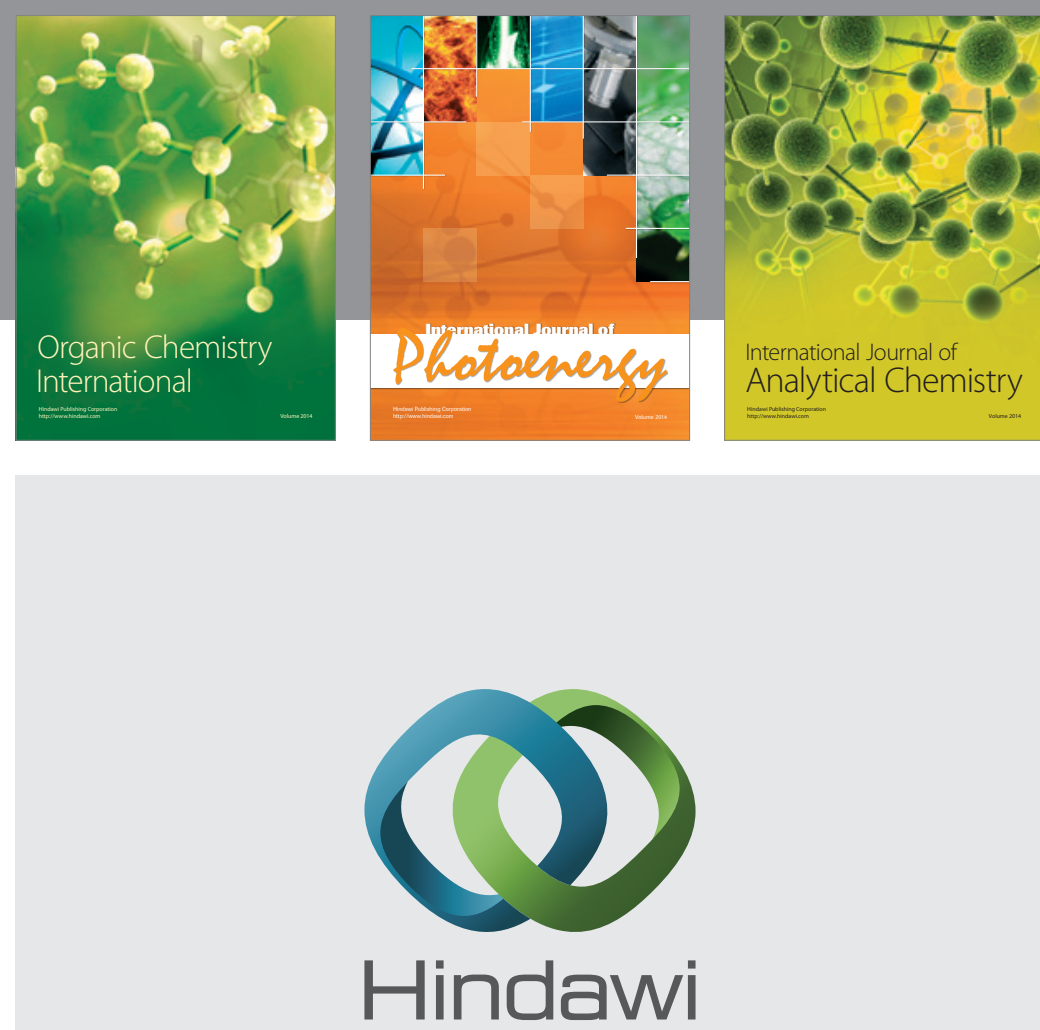

Submit your manuscripts at

http://www.hindawi.com
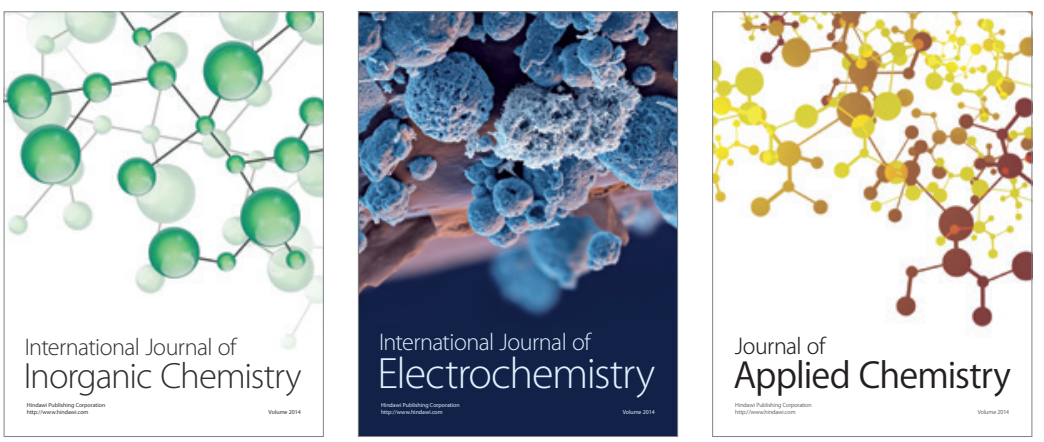

Journal of

Applied Chemistry
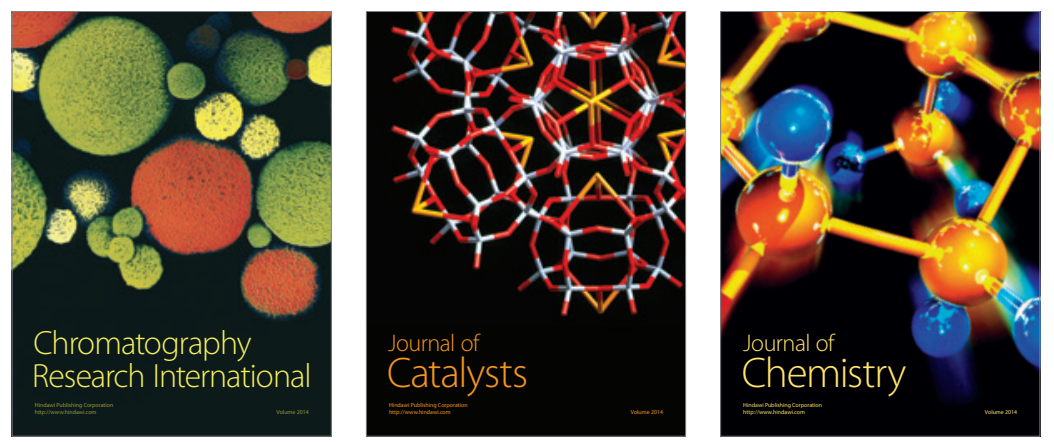
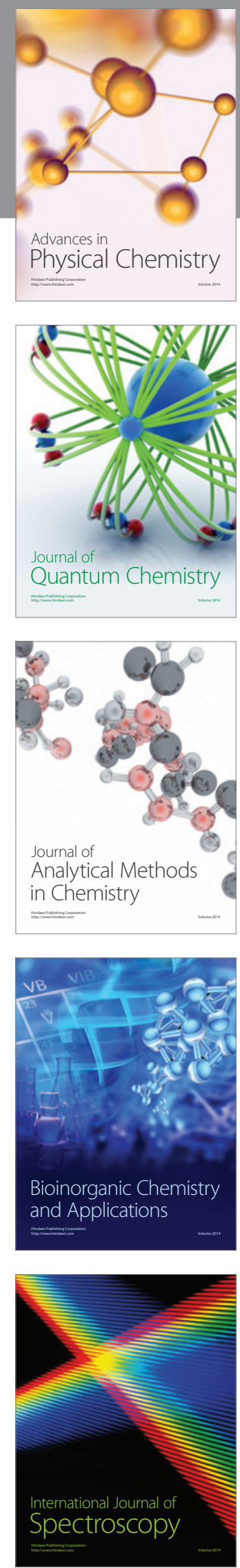